\title{
Pesticide Toxicity Profile: Phosphorous and Sulfur Fumigants ${ }^{1}$
}

Frederick M. Fishel ${ }^{2}$

This document provides a general overview of human toxicity, a listing of laboratory animal and wildlife toxicities, and a cross reference of chemical, common and trade names of phosphorous and sulfur fumigants registered for use in Florida.

\section{General}

These groups of fumigants have been used for many years throughout the world, including the United States. The chemical family of phosphorous fumigants consists of two members - aluminum and magnesium phosphide, both of which liberate phosphine gas, while sulfuryl fluoride is a sulfur-based material. As a fumigant group, they are some of the most important pest control tools used in the world. They are active on all life stages of insects and penetrate air spaces where other types of pesticides don't reach. Their classification is restricted use due to their acute toxicity (toxicity category I) and the label's signal word is "DANGER."
The phosphorous fumigants are registered for use on food and feed commodities, including grains, animal feeds, coffee, and nuts. Aluminum phosphide was first registered in the U.S. in 1958 and magnesium phosphide followed in 1979. Non-food uses include tobacco and outdoor fumigation for burrowing rodent and mole control. They are formulated as several types of solid materials, such as pellets and tablets. Upon exposure to heat and moisture, they release their toxic gas. At temperatures below $40^{\circ} \mathrm{F}$, the gas release is poor and the effectiveness is lost. One reason why they have been prominently used is that at normal use rates, they do not affect seed germination. Another reason is their ease of application. By calculating the volume of space to be fumigated, the directions will state how much material should be placed within the site. Phosphine is about $20 \%$ heavier than air, thus fans to disperse the gas are unnecessary except in large bulk facilities. It takes 3 to 5 days for phosphine fumigation to be complete under warm, humid conditions. Aeration can be done in a relatively short time, only 1 to 2 hours.

1. This document is PI-73, one of a series of the Pesticide Information Office, Florida Cooperative Extension Service, Institute of Food and Agricultural Sciences, University of Florida. Published September 2005. Visit the EDIS Web Site at http://edis.ifas.ufl.edu.

2. Frederick M. Fishel, Associate Professor, Agronomy Department, and Director, Pesticide Information Office; Florida Cooperative Extension Service, Institute of Food and Agricultural Sciences, University of Florida, Gainesville, FL 32611.

The use of trade names in this publication is solely for the purpose of providing specific information. UF/IFAS does not guarantee or warranty the products named, and references to them in this publication does not signify our approval to the exclusion of other products of suitable composition. Use pesticides safely. Read and follow directions on the manufacturer's label.

The Institute of Food and Agricultural Sciences (IFAS) is an Equal Opportunity Institution authorized to provide research, educational information and other services only to individuals and institutions that function with non-discrimination with respect to race, creed, color, religion, age, disability, sex, sexual orientation, marital status, national origin, political opinions or affiliations. U.S. Department of Agriculture, Cooperative Extension Service, University of Florida, IFAS, Florida A. \& M. University Cooperative Extension Program, and Boards of County Commissioners Cooperating. Larry Arrington, Dean 
Sulfuryl fluoride is a structural fumigant for sites such as dwellings, transport vehicles, rail cars, and ships; it is an odorless gas stored in cylinders under pressure. It is not registered for use on food or feed crops. It is not effective on insect eggs or at temperatures below $55^{\circ} \mathrm{F}$. Because sulfuryl fluoride is odorless, a warning agent, such as chloropicrin, can be added to the gas.

\section{Toxicity}

Phosphine gas is extremely irritating to the respiratory tract. It also produces severe systemic toxicity. Most severe acute exposures have involved ingestion of the solid aluminum phosphide, which converts rapidly to phosphine gas by acid hydrolysis in the stomach. Poisoning due to ingestion carries a mortality rate of 50 to $90 \%$. Poisonings had become frequent during the late 1980s and early 1990s in some parts of India. Symptoms of poisoning include fatigue, nausea, headache, dizziness, thirst, cough, shortness of breath, chest tightness, and loss of heartbeat in severe cases. The common cause of death is by excessive fluid buildup in the lungs. Chronic toxicity due to phosphine gas appears to be minor or have a very long latency period. The available evidence for reproductive effects in animals suggest that reproductive effects are not likely in humans under normal conditions. Animal data also suggest that phosphine would not be likely to cause teratogenic effects in humans. No evidence was available regarding the ability of aluminum phosphide or phosphine to cause mutations or increase the mutation rate. No data are currently available which evaluate its carcinogenic effects.

Sulfuryl fluoride exposure has caused some deaths, primarily by individuals entering fumigated structures without respiratory protection. Symptoms of poisoning include nose, eye and throat irritation, weakness, nausea, vomiting, cough, restlessness, muscle twitching and seizures. Rats, rabbits, guinea pigs and female rhesus monkeys tolerated air concentrations of $100 \mathrm{ppm}\left(417 \mathrm{mg} / \mathrm{m}^{3}\right)$ for 7 hours per day, 5 days a week for 6 months with no apparent adverse effects. There have been no reproductive, teratogenic, or mutagenic effects reported from sulfuryl fluoride exposure, and carcinogenicity data do not exist at the time of this publication.
Mammalian toxicities for the phosphorous and sulfur fumigants are shown in Table 1. Table 2 lists the toxicities to wildlife, if known, by the common name of the pesticide. Because these fumigants are labeled for indoor use, compliance with label directions will limit exposure to wildlife, thus little data are available. Table 3 provides a cross listing of some of the trade names that these products are registered and sold by in Florida.

\section{Additional Information}

Crop Protection Handbook. 2005. vol. 91. Willoughby, Ohio: Meister Publishing Co. http://www.meisterpro.com/mpn.

Hayes, W.J. and E.R. Laws (eds.). 1990. Handbook of pesticide toxicology, classes of pesticides, vol. 3. Academic Press, Inc., NY.

Nesheim, O.N. 2002. Toxicity of pesticides. UF/IFAS EDIS Document PI-13. http://edis.ifas.ufl.edu/PI008.

Reigart, J.R. and J.R. Roberts. 1999. Recognition and management of pesticide poisonings, $5^{\text {th }}$ ed. United States Environmental Protection Agency Publication EPA-735-R-98-003.

Seyler, L.A., et.al. 1994. Extension toxicology network (EXTOXNET). Cornell University and Michigan State University. http://extoxnet.orst.edu/index.html. Visited September 2005. 
Table 1. Phosphorous and sulfur fumigant mammalian toxicities ( $\mathrm{mg} / \mathrm{kg}$ of body weight).

\begin{tabular}{||l|c|c||}
\hline \hline Common name & Rat $^{\text {oral LD }}{ }_{\mathbf{5 0}}$ & Inhalation LC $_{\mathbf{5 0}}$ \\
\hline Aluminum phosphide & $11.5($ Phostoxin $\AA)$ & 10.7 \\
\hline Magnesium phosphide & $9.1($ Magtoxin $\AA)$ & 180 \\
\hline Sulfuryl fluoride & 100 & 991 \\
\hline \hline
\end{tabular}

Table 2. Phosphorous and sulfur fumigant wildlife toxicity ranges.

\begin{tabular}{|c|c|c|c|}
\hline Common name & Bird acute oral $\mathrm{LD}_{50}(\mathrm{mg} / \mathrm{kg})^{\star}$ & Fish $(p p m)^{\star \star}$ & $\mathrm{Bee}^{\dagger}$ \\
\hline Aluminum phosphide & --- & VHT & --- \\
\hline Magnesium phosphide & --- & --- & --- \\
\hline Sulfuryl fluoride & --- & --- & PNT \\
\hline \multicolumn{4}{|c|}{ 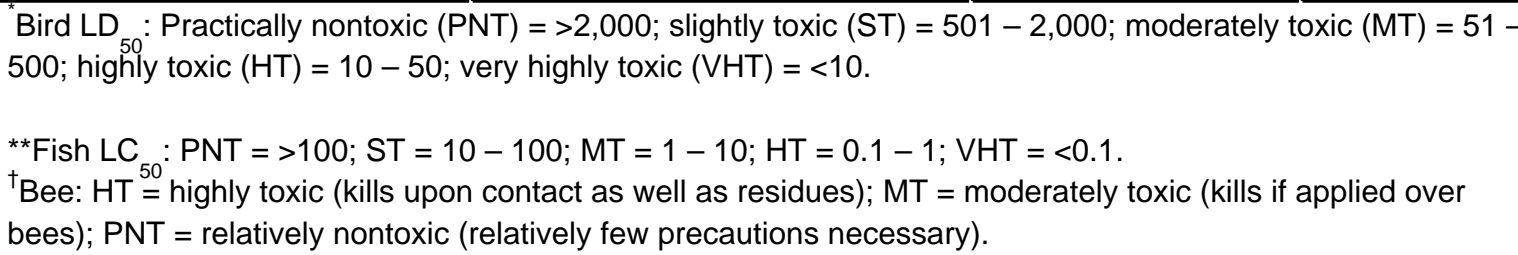 } \\
\hline
\end{tabular}

Table 3. Cross reference list of common, trade and chemical names of phosphorous and sulfur fumigants.

\begin{tabular}{||l|l|l|}
\hline \hline Common name & Trade names & Chemical name \\
\hline Aluminum phosphide & $\begin{array}{l}\text { Phostoxin } \AA \text {, Detiaphos } \AA, \\
\text { Phosfume } \AA \text {, Fumitoxin } \AA \text {, Gastoxin } \AA, \\
\text { Phosfume } \AA \text {, Weevilcide } \AA\end{array}$ & Aluminum phosphide \\
\hline Magnesium phosphide & Fumi Cel $\AA$, Fumi Strip $\AA$, Magtoxin $\AA$ & Magnesium phosphide \\
\hline Sulfuryl fluoride & Vikane $\AA$ & Sulfuryl fluoride \\
\hline \hline
\end{tabular}

